\title{
Mapping the Motion Space of Children in Autism Treatment Center of Malang City with TEACCH Approach (Treatment and Education of Autistic and Related Communication Handicapped Children)
}

\author{
Rinawati Pudji Handajani', Rizky N. H. Pramesti² \\ 1,2 Department of Architecture, Faculty of Engineering, Universitas Brawijaya, Malang, Indonesia \\ rinawatinoor@yahoo.co.id
}

\begin{abstract}
The Autism Treatment Center in Malang City applies structured teaching-learning methods, namely the TEACCH approach (Treatment and Education of Autistic and Related Communication Handicapped Children) with four essential components: physical structure, schedule, work system, and visual structure. The four components are interrelated with each other so that the goal of helping the development of autistic children can be achieved. The physical structure is the first step to encourage the interest of autistic children. An excellent physical arrangement of space can minimize the tantrum effect of autistic children. Thus, this paper aims to research the space for autistic children with the TEACCH approach. This study used behavioral mapping in the form of person-centered mapping, place centered mapping, and physical trace that aims to determine the pattern of activity, furniture layout, and trace activities of autistic children during therapy activities. The results show the motion space mapping of autistic children.
\end{abstract}

Keywords: Anthropometry, autism, motion space, TEACCH

\section{Introduction}

The growth of autistic children in Indonesia has increased. According to the Directorate of Mental Health, Ministry of Health, Republic of Indonesia, as of 2010, the number of autistic children in Indonesia are about 112,000 children by ages of 5-19 years old. These numbers were derived from the prevalence of 1.68 per 1000 children under 15 years old. Meanwhile, the number of children in Indonesia is 66 million (BPS, 2010).

All children have the right to get an education, no exception the autistic children. To support the development of autistic children, the government has provided Autism Treatment Centers, which established in several cities in Indonesia, including Malang City. The Autism Treatment Center in Malang has applied a structured teaching method, namely the TEACCH approach, with four essential components: physical structure, schedule, work system, and visual structure. The four components are interrelated with each other so that the goal of helping the development of autistic children can be achieved. The physical structure is the first step to encourage the interest of autistic children. An excellent physical arrangement of space can minimize the tantrum effect of autistic children. The physical structure relates to the motion space. The motion space is derived from anthropometry of the autistic children, activity, and the number of users. The focus of the research is the Intervention Class as the primary class for autistic children who could not interact, communicate, and adapt to their environment. Thus, much attention must be paid to support the development of autistic children. Therefore, the conformity of motion space for autistic children is required to create a comfortable and secure space for autistic children during therapy activity.

The objective of the research was to study conformity of the motion space for autistic children in Intervention Class at the Autism Treatment Center in Malang City with 
the TEACCH approach by calculating the motion space through anthropometry of the autistic children and activities during the therapy. Some theoretical reviews which support this research are as follow.

\subsection{Motion Space}

In applying the structured teaching-learning method with the TEACCH approach, one of the most important components is a physical structure. It requires a classroom with apparent partition positioning, which is not confusing autistic children. Space with physical arrangement will minimize the tantrum effect of autistic children. It requires classrooms with a specific width, which conforms to the motion space and anthropometry for autistic children. There are two ways of measuring the human dimension. First is the static dimension, in which the subject is in static condition and good standard position when they stand and sit, and second is the dynamic dimension, in which the subject is in moving condition (Panero and Zelnik, 1979).

\subsection{Characteristics of the Autistic Children}

According to Handojo (2003), autistic children have over-selective characteristics against stimulation, lack of motivation to explore the new environment, and selfstimulation response. Thus, they have difficulties in social integration and have different responses to reward, especially reward from self-stimulation. Besides, Sugiarmin (2005) suggested that characteristics of the autistic children include disorders in communication, social interaction, behavior, emotion, and sensory or sensory perception.

\subsection{Personal Space of the Autistic Children}

Autistic children have weaker social interactions and different personal space from normal children. They may have difficulties arranging space with other individuals during social interaction (Gessaroli in Naumi, 2016). They also have difficulties interacting closely with others, especially strangers. Thus, the personal space of autistic children is wider than normal children. According to Naumi (2016), the personal space of autistic boys with the confederate of males and females ranges $45-90 \mathrm{~cm}$. The personal space of the autistic girls with the confederate of males ranges $90 \mathrm{~cm}-2 \mathrm{~m}$. While the personal space of the autistic girls with the confederate of female ranges $90-120 \mathrm{~cm}$. Naumi (2016) suggested that coloring together may shorten the personal space between autistic children and others. This method is intended to increase communication development when they interact with their surroundings.

Personal space of normal human or proxemic distance, according to Hall (1966), referred to a study about the position and distance of the body. There are four variations of spatial behavior or which so-called proxemic distance. Those four zones are intimate distance, personal distance, social distance, and public distance.

Table 1. Proxemic Distance

\begin{tabular}{|c|c|c|c|c|c|c|c|}
\hline \multicolumn{8}{|c|}{ Distance } \\
\hline \multicolumn{2}{|c|}{ Intimate } & \multicolumn{2}{|c|}{ Personal } & \multicolumn{2}{|c|}{ Social } & \multicolumn{2}{|c|}{ Public } \\
\hline Close Phase & Far Phase & Close Phase & Far Phase & Close Phase & Far Phase & Close Phase & Far Phase \\
\hline $0-15 \mathrm{~cm}$ & $15-45 \mathrm{~cm}$ & $45-75 \mathrm{~cm}$ & $75-120 \mathrm{~cm}$ & $120-210 \mathrm{~cm}$ & $210-360 \mathrm{~cm}$ & $360-750 \mathrm{~cm}$ & $>750 \mathrm{~cm}$ \\
\hline
\end{tabular}

\subsection{Anthropometry of the Autistic Children}

Anthropometry is derived from the Roman language 'anthropos', which means human and 'metron' means measurement. Thus, anthropometry is a measurement of the 
human body (Bridger, 1995), a part of a study on the human body dimension (Pulat, 1997), or a study that relates to the physical character and dimension of the human body (Tayyari and Smith, 1997). Anthropometry is used as a basis to design so that conformity between design and user can be achieved (Panero and Zelnik, 1979). Dimensional variability of the human body is affected by some factors, such as age, gender, race/ethnicity, profession, local environment. Design for children is different from design for adults. Thus, the age factor must be concerned to make the users feel comfortable.

The height of autistic children grows faster than normal children. The bone growth pattern of autistic children tends to grow faster in length or height (Chawarska et al., 2011). Autistic children tend to grow faster, shown by different sizes of head, height, and body weight compared with normal children. Therefore, the anthropometry of autistic children is indirectly different from the anthropometry of normal children. Empiric data of anthropometry on autistic children has not been found yet (Naumi, 2016).

There are few anthropometry data on normal babies and normal children by ages 6-11 years old (Panero and Zelnik, 1979). Anthropometry data include body weight and height, height in an upright sitting position, stretch of an elbow to elbow, stretch of the pelvis, the height of thigh, height of the knee, height of the hollow knee, space between buttocks-hollow knee, and space between buttock-knee. The data is categorized by age, gender, and selection percentile.

\subsection{Structured Teaching with TEACCH Approach}

The Learning Module of PLB Autism Bandung suggested that structured teaching is a learning method based on the TEACCH (Treatment and Education of Autistic and Communication Handicapped Children) approach. In its implementation, TEACCH refers to the ability, interest, and needs of the children individually. However, the objective of structured learning is self-supporting (Indocare, 2010). The most important thing in the TEACCH program is structured teaching (Schopler in Nurina, 2015). There are four important components in a structured teaching-learning method, namely physical structure, schedule, work system, and visual structure. The physical structure is the first step to encourage the interest of autistic children. An excellent physical arrangement of space can minimize the tantrum effect of autistic children (Nurina, 2015). The schedule must be comprehensible so that autistic children will not be confused. In the structured teaching program with the TEACCH approach, autistic children were given PECS schedule boards to help them shift from one activity to the other. Also, the work system must be understandable and specific to assist autistic children in completing their assignments on their own in self-supported and organized ways. Autistic children will recognize activities, which must be completed. Thus, they will be able to move to the directed end, from one activity to another. Visual structure applies picture media or photographs to facilitate communicating with autistic children. The applied media include stopping place for photographs of the children, PECS (Picture Exchange Communications System), ALS (Aided Language Stimulation), among others. If those four components are fulfilled, the autistic children would not feel bored (Nurina, 2015). When the autistic children feel comfortable, both therapy activity and learning will run effectively without any tantrum.

\section{Method}

The research applied a descriptive qualitative method, which was conducted for a month. Observation and problem-searching were conducted during the first and second weeks, measuring and sketch making in the third week, and activity mapping in the fourth week. And then, both primary and secondary data were collected. Primary data includes observation, interview, and behavioral mapping (person-centered mapping, place 
centered mapping, and physical trace). Secondary data include works of literature from journals, books, and thesis. After that, it was followed by data analysis, which includes individuals who conduct the activity, autistic children's activities, anthropometry of the autistic children, and motion space of the autistic children. Steps of the data analysis were conducted in chronological order to obtain an appropriate measure of anthropometry for autistic children and space width that conforms to the motion space of the autistic children.

\section{Result and Discussion}

The research object is the Autism Treatment Center (PLA) of Malang City on Jalan Raya Tlogowaru, Kedungkandang District, Malang. The research examined nine indoor rooms, which were used for intervention class, namely Room 1 on 1, Room 1 on 2, Grouping Room, Motoric Room on 1st floor, Motoric Room on 2nd floor, Self-Building Room, Playground on 1st floor, Playground on 2nd floor, and Snoezelen Room. The research took the intervention class as a sample of the research, which comprised Kelas Awan (Cloud Class) and Kelas Pelangi (Rainbow Class). As the children ages range 5-11 years old, the average age for the intervention group was taken to determine the calculation of anthropometry for autistic children. The equation to calculate the average age of the children is given below.

$$
\text { average age }=\frac{\text { Number of age }}{\text { Number of students }}
$$

Sample of ages was taken following the average age of the intervention group; the age of 8 years old was taken as a reference to calculate anthropometry of the autistic children. The behavioral mapping was used to find out the children's activities in each room, including person-centered mapping, place centered mapping, and physical trace. The result of mapping for each child are then overlaid to find out the children's behaviors.

The rooms, which will be explained in detail on the analysis stage, are Room 1 on 1 , Room 1 on 2, and Grouping Room (Table 2). Those three rooms represent the analysis stage for other rooms. The other six rooms showed the results as follows: Motoric Room on 1st floor is $100 \%$, Motoric Room on 2nd floor is $75 \%$, Self-Building Room is $50 \%$, playground on 1 st floor is $25 \%$, playground on 2 nd floor is $25 \%$, and Snoezelen Room is $75 \%$.

Table 2. Analysis on Activities of the Autistic Children

\begin{tabular}{|c|c|c|c|c|}
\hline \multirow{2}{*}{ No } & \multirow{2}{*}{ Method } & \multirow{2}{*}{ Figure } & \multicolumn{2}{|c|}{ Activity } \\
\hline & & & Normative & Less Normative \\
\hline \multicolumn{5}{|c|}{ Room 1 on 1} \\
\hline 1. & $\begin{array}{l}\text { Activity } \\
\text { Overlay }\end{array}$ & 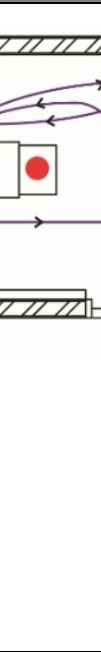 & $\begin{array}{l}\text { 1. Attaching photograph on the } \\
\text { stopping place for the } \\
\text { photograph of the children } \\
\text { 2. Walking toward the children } \\
\text { seat } \\
\text { 3. Doing activities that conform to } \\
\text { the learning program (making } \\
\text { tassels, puzzle, tie the colors, } \\
\text { reading, writing) } \\
\text { 4. After attending learning } \\
\text { activity, the children will tidy } \\
\text { up their seats and tables } \\
\text { 5. Taking pictures at the stopping } \\
\text { place for the photograph of the } \\
\text { children, and then move to the } \\
\text { next classroom }\end{array}$ & $\begin{array}{l}\text { 1. Attaching photograph on the } \\
\text { stopping place for the } \\
\text { photograph of the children } \\
\text { 2. The children approach the } \\
\text { media rack because they are } \\
\text { easily distracted to object, } \\
\text { which attracts their attention. } \\
\text { 3. Walking toward the children } \\
\text { seat } \\
\text { 4. Doing activities that conform to } \\
\text { the learning program (making } \\
\text { tassels, puzzle, tie the colors, } \\
\text { reading, writing) } \\
\text { 5. The children will tidy up their } \\
\text { seats and tables } \\
\text { 6. Taking pictures at the stopping } \\
\text { place for the photograph of the } \\
\text { children, and then move to the } \\
\text { next classroom }\end{array}$ \\
\hline
\end{tabular}




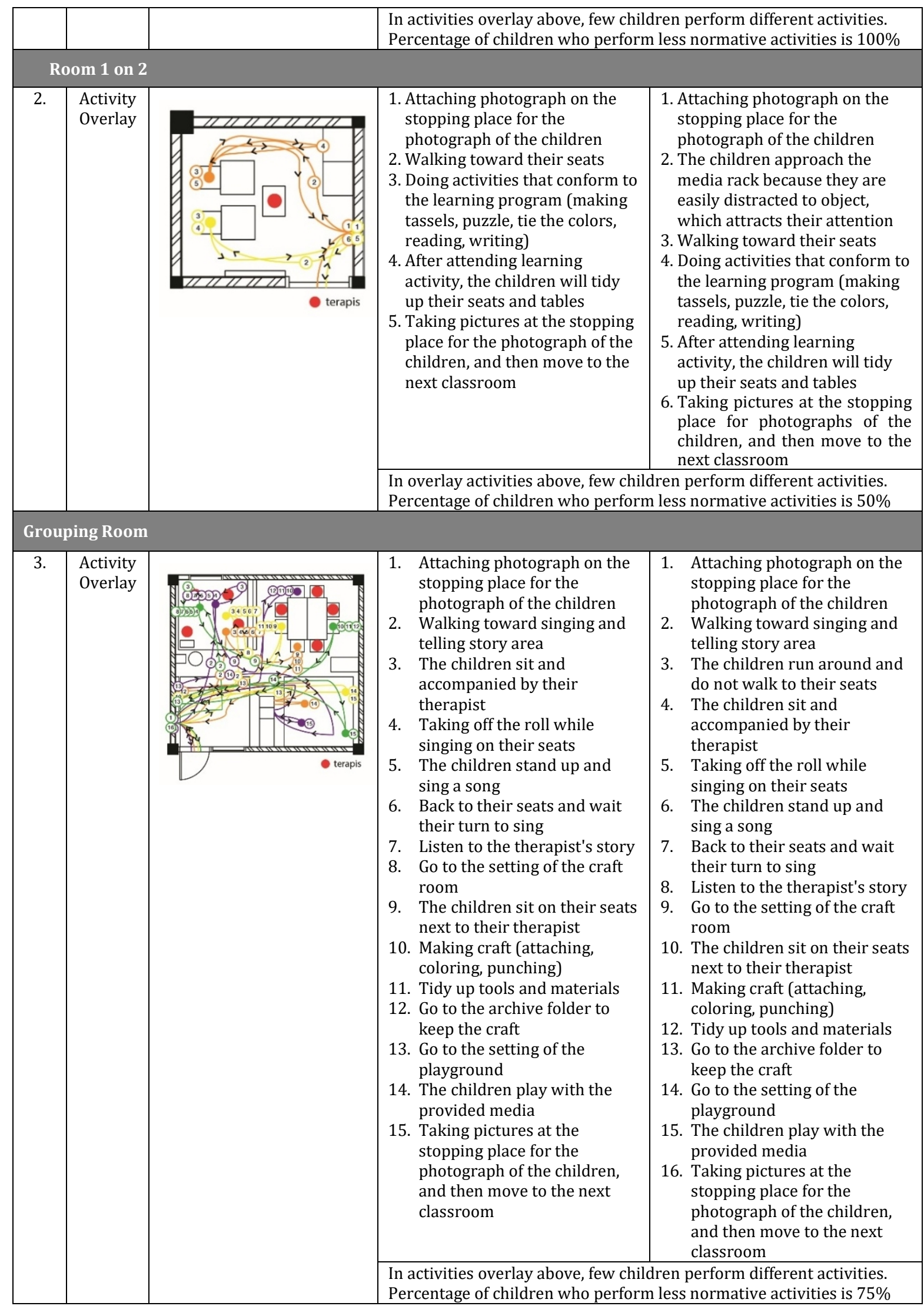


Based on the analysis of the autistic children's activities above, it indicated activities in each room, which were performed by the autistic children of the intervention group. Thus, such activities could be used to count the motion space of autistic children. The motion space of autistic children was obtained from observation on the position of the basic motion. The position of basic motion is divided into static motion (non-locomotors) and dynamic motion (locomotors). The measurement of anthropometry on autistic children is different from normal children. Thus the measurement should be taken following the observation on the location of the research. According to the book of Dimension of Human and Interior Space, the average height of normal children, eight years old, without any autistic disorders is about $129.6 \mathrm{~cm}$. Based on the previous research, the autistic children grow faster than normal children. Thus, autistic children are taller than normal children. Based on the observation and measurement results, the average height of autistic children, eight years old, is $130 \mathrm{~cm}$.

The table of anthropometry analysis on autistic children presents the width of motion space for autistic children, derived from static and dynamic motions during therapy activity. Space width is calculated from the anthropometry of the autistic children, activity, and number of persons in each room. In calculating the space width, there are four zones: personal space, safe zone, activity zone, and circulation zone.

Personal space is the zone with a specific distance/space with others that makes autistic children feel comfortable. Following the previous research, the personal space of the autistic boys with the confederate of males and females ranges $45-90 \mathrm{~cm}$. The personal space of the autistic girls with the confederate of males ranges $90 \mathrm{~cm}-2 \mathrm{~m}$. While the personal space of the autistic girls with the confederate of female ranges $90-120 \mathrm{~cm}$. Thus, the research results showed numbers as follows: $45 \mathrm{~cm}, 90 \mathrm{~cm}, 120 \mathrm{~cm}$, and $2 \mathrm{~m}$. However, $45 \mathrm{~cm}$ is the shortest personal space of the autistic children during therapy activity. The distance is used to calculate the motion space of autistic children to shorten the personal space of the autistic children with others.

The activity zone is the zone where the autistic children perform their activities during therapy activity. Circulation zone is an area for their movement during the activity. The children's body frontage width is $26 \mathrm{~cm}$, and the body frontage width of the adult is 35 $\mathrm{cm}$. Thus, the wider space or distance, $35 \mathrm{~cm}$, is used as a circulation zone because it could cover the small measure.

The safe zone is $10 \mathrm{~cm}$ to give space for the autistic children to avoid hitting the wall in the therapy room. Each room is intended to provide a place for a different activity. Thus, the space width is determined by the wider motion space of activities in each room. Motion space with the highest activities may give shelter the motion space of the least activities.

Table 3. Analysis of the Motion Space of Autistic Children

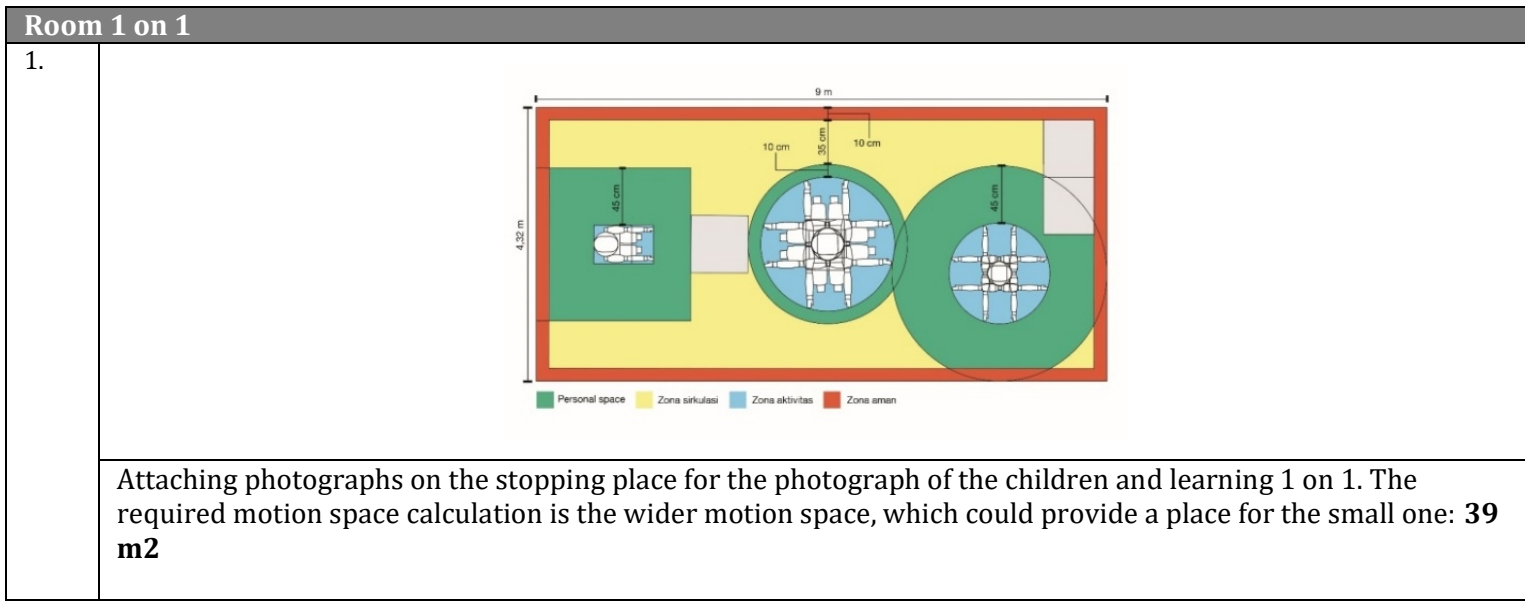

Jurnal RUAS Volume 18 No. 1 Juni 2020 ISSN 1693-3702 E-ISSN 2477-6033 


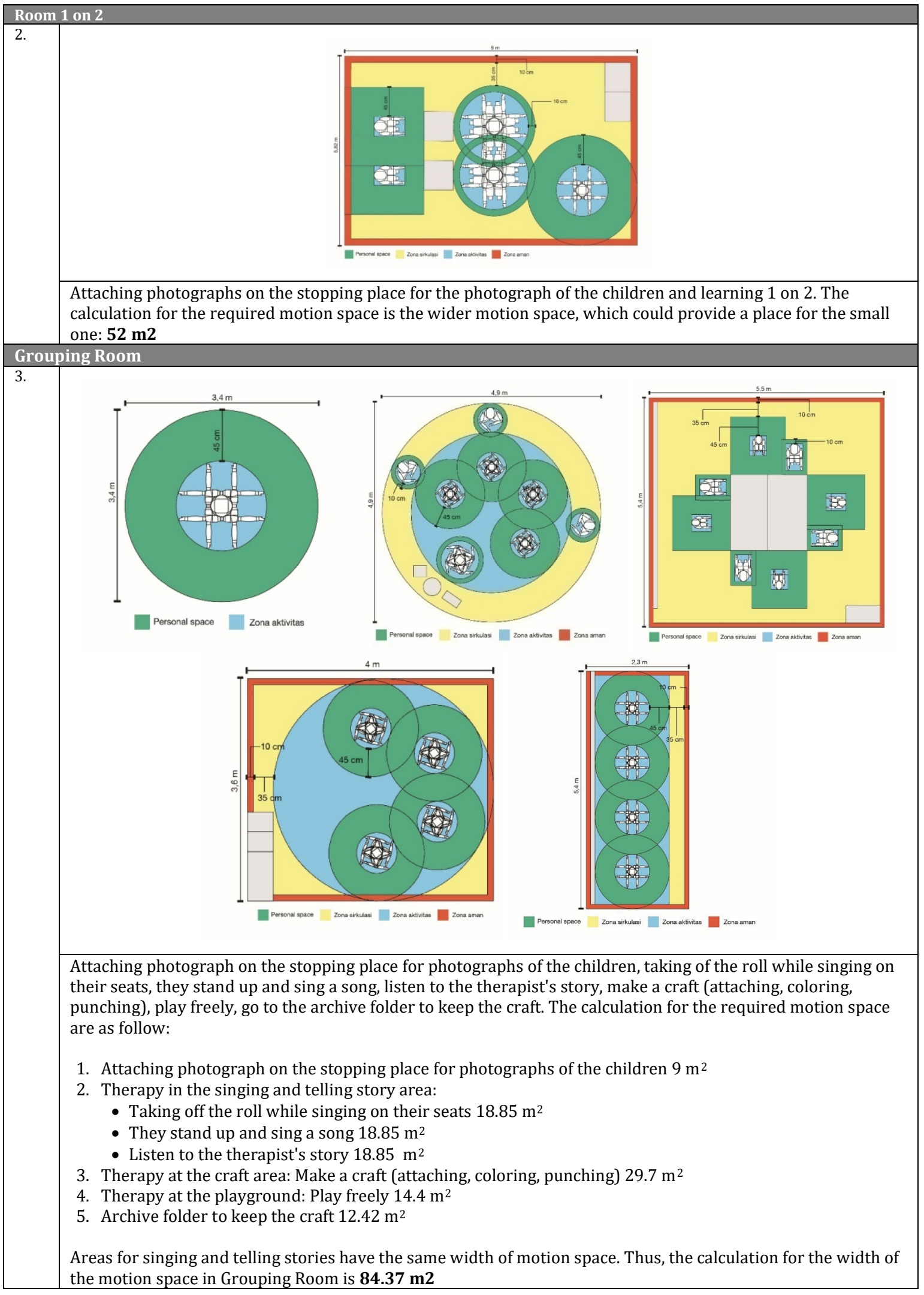

The other six rooms showed the results as follows: Motoric Room (1st floor) is $50.47 \mathrm{~m} 2$, Motoric Room (2nd floor) is $46.43 \mathrm{~m} 2$, Self-Building Room is $37.94 \mathrm{~m} 2$, playground (1st floor) is $31.79 \mathrm{~m} 2$, playground (2nd floor) is $22.88 \mathrm{~m} 2$, and Snoezelen Room is $41.12 \mathrm{~m} 2$. 
Based on the analysis of the motion space above, it shows the space width is following the kinds of activity and motion space of the autistic children. Thus, it can compare the space width, which conforms to the motion space of autistic children with the existing space width in the Autism Treatment Center in Malang City. Table of space width comparison based on the need for motion space for the children and the existing space width.

Table 4. Comparison of the Space Width

\begin{tabular}{|c|c|c|c|c|}
\hline \multirow[b]{2}{*}{ Therapy Room } & \multicolumn{2}{|c|}{ Analysis of Motion Space } & \multicolumn{2}{|c|}{ Existing Condition } \\
\hline & $\begin{array}{c}\text { Space Width } \\
\left(\mathrm{m}^{2}\right)\end{array}$ & $\begin{array}{l}\text { Motion Space } \\
\text { per Child }\left(\mathrm{m}^{2}\right)\end{array}$ & $\begin{array}{c}\text { Space Width } \\
\left(\mathrm{m}^{2}\right)\end{array}$ & $\begin{array}{l}\text { Motion Space } \\
\text { per Child }\left(\mathrm{m}^{2}\right)\end{array}$ \\
\hline R. 1 on $1^{*}$ & 39 & 39 & 4.72 & 4.72 \\
\hline R. 1 on $2^{*}$ & 52 & 26 & 4.44 & 2.22 \\
\hline Grouping Room* & 84.37 & 21.09 & 23.6 & 5.9 \\
\hline Motoric Room $1^{\text {st }}$ Floor* & 50.47 & 25.24 & 21.55 & 5.39 \\
\hline Motoric Room 2nd Floor* & 46.43 & 11.61 & 46.08 & 11.52 \\
\hline Self-Building Room* & 37.94 & 9.49 & 22.49 & 5.62 \\
\hline Playground on $1^{\text {st }}$ Floor* & 31.79 & 7.95 & 23.22 & 5.81 \\
\hline Playground on 2nd Floor & 22.88 & 5.72 & 50.58 & 12.64 \\
\hline Snoezelen Room* & 41.12 & 10.28 & 11.23 & 2.81 \\
\hline
\end{tabular}

Notes: * have not fulfilled the need of motion space

Based on Table 4, it can be concluded that out of 9 existing rooms in the Autism Treatment Center in Malang, eight rooms are smaller than the space width, following the calculation of the motion space. Furthermore, the restroom is larger than the space width, following the calculation of the motion space. Thus, it can be shown that those eight existing rooms have not conformed to the calculation of the motion space of the autistic children.

\section{Conclusion}

The research was conducted at the Autism Treatment Center in Malang that locates on Tlogowaru Highway, Kedungkandang District, Malang. There are nine indoors as the focus of the research, namely Room 1 on 1, Room 1 on 2, Grouping Room, Motoric Room (1st floor), Motoric Room (2nd floor), Self-Building Room, Playground (1st floor), Playground (2nd floor), and Snoezelen Room. The initial stage of observation is identifying the space function and activity conducted by the space user and the layout of the furniture.

After the data was collected, it requires an analysis of the person who performs the activity. The research took the intervention class as a sample of the research, which comprised of Kelas Awan (Cloud Class) and Kelas Pelangi (Rainbow Class). The ages in this class range 5-11 years old, 28 children. Due to the children have different ages, the average age is taken to determine the calculation of anthropometry for autistic children. Thus, eight years old is the average age used as a standard of anthropometry calculation of the autistic children.

The next stage is the analysis on the autistic children's activity using behavioral mapping method, namely person-centered mapping, place centered mapping, and physical trace. Person-Centered mapping aims to determine the pattern and kinds of activity of the autistic children during therapy activity. Place centered mapping is aimed to find out the conformity of the space and layout of the furniture. Physical traces are used to determine the physical trace of the autistic children when they are in the therapy room.

After discovering activities performed by the autistic children, it can be used to recognize motion space of the autistic children. The motion space of autistic children was 
obtained from observation on the position of the basic motion in the research location. The position of basic motion is divided into static motion (non-locomotors) and dynamic motion (locomotors). The measurement of anthropometry on autistic children is different from normal children. Based on the previous research, the autistic children grow faster than normal children. Following the results of observation and measurement, the average height of autistic children, eight years old, is $130 \mathrm{~cm}$.

The width of motion space for autistic children was derived from the position of static and dynamic motions during therapy activity. In calculating the motion space of the autistic children, there are four zones, namely personal space, safe zone, activity zone, and circulation zone. Following the previous research, the personal space of the autistic children in this research is $45 \mathrm{~cm}$. In this distance or spacing, the autistic children will feel comfortable during therapy activity. The activity zone is the zone where the autistic children perform their activities. The circulation zone is an area for their movement during the activity, $35 \mathrm{~cm}$. This distance is taken from the wider body frontage width of the adult. The safe zone is $10 \mathrm{~cm}$ in order to avoid the autistic children hitting the wall in the therapy room.

The result of the research indicated that the space width at the Autism Treatment Center in Malang has not conformed to the need for motion space for autistic children. Width of the motion space has not fulfilled the anthropometry calculation for the autistic children and activity during the therapy. Thus, it makes the therapy process has not run optimally.

\section{References}

BPS - Statistics Indonesia. (2010) Statisik Indonesia -Statistical Yearbook of Indonesia 2010.

https://www.bps.go.id/publication/2010/12/23/b0adeb45e05c3db10ac99f33/stat istik-indonesia-2010.html

Bridger, RS. (1995). Introduction to Ergonomics. McGraw-Hill, Inc.

Chawarska K, Campbell D, Chen L, Shic F, Klin A, Chang J. (2011). Early generalized overgrowth in boys with autism. Arch Gen Psychiatry. 68(10):1021-1031. doi:10.1001/archgenpsychiatry.2011.106

Hall, Edward T. (1966). The Hidden Dimension. Anchor Books. ISBN 978-0-385-08476-5.

Handojo, Y. (2003). Autisme. Jakarta. PT. Bhuana Ilmu Populer Kelompok Gramedia.

Indocare. (2010). Manajemen Pembelajaran Terstruktur. Jakarta: Indocare.

Naumi, F. I. (2016). Personal Space on Children (Review on the Autistic Children and Normal Children).

Nurina, P., (2015). Islamic Education for the Autistic Students in Inclusive School. South Tangerang: Young Progressive Muslim.

Panero J., M. Zelnik. (1979). Human Dimension. Jakarta: Erlangga.

Pulat, B Mustafa. (1997). Fundamental of Industrial Ergonomics 2nd Edition. Waveland Press Inc.

Sugiarmin, M. (2005). Individu dengan Gangguan Autisme. PLB UPI.

Tayyari, F. And Smith, J.L. (1997). Occupational Ergonomics: Principles and Aplications, London: Chapman \& Hall. 